\title{
The relationship between qualitative job insecurity and OCB: Differences across age groups
}

Economic and Industrial Democracy

$0(0) \mathrm{I}-23$

(C) The Author(s) 2013

Reprints and permissions: sagepub.co.uk/journalsPermissions.nav DOI: $|0.1| 77 / 0|4383| X \mid 3510326$ eid.sagepub.com

(SAGE

\section{Dave Stynen}

Maastricht University, The Netherlands; KU Leuven, Belgium

\section{Anneleen Forrier}

KU Leuven, Belgium

\section{Luc Sels}

KU Leuven, Belgium

\section{Hans De Witte}

KU Leuven, Belgium; North-West University, South Africa

\begin{abstract}
Qualitative job insecurity may be associated with less (hindrance effect) and more (challenge effect) organizational citizenship behaviour (OCB). This article disentangles both effects by introducing an intermediate variable. The authors test whether basic need satisfaction explains the hindrance effect (i.e. less intrinsically motivated $O C B$ ); and whether there is a remaining, direct positive path to OCB reflecting the challenge effect (i.e. more instrumentally motivated $\mathrm{OCB}$ ). In addition, they investigate whether these relationships vary with age. Multi-group path analysis on a Belgian sample $(N=3243)$ of young ( $18-30$ years), prime age ( 3 I-49 years) and mature age workers $(50+)$ reveals that qualitative job insecurity frustrates basic needs across all age groups, but most strongly among mature age workers (i.e. hindrance effect). The authors find a remaining positive path (i.e. challenge effect) that is equally strong across all age groups. In sum, qualitative job insecurity is more hindering than challenging, in particular for older workers.
\end{abstract}

\section{Keywords}

Basic need satisfaction, job insecurity, OCB (organizational citizenship behaviour), older worker, stressors

\section{Corresponding author:}

Dave Stynen, Maastricht University, Peter Debyeplein I, PO Box 616, 6200 MD, Maastricht, The Netherlands. Email: dave.stynen@maastrichtuniversity.nl 
Inspired by the many organizational restructurings and downsizings during the past decades, the job insecurity literature has directed most attention to threats of imminent job loss, i.e. quantitative job insecurity (De Witte et al., 2010). However, this volatile organizational landscape also gave rise to qualitative job insecurity. Many workers are not insecure about losing their jobs, but fear a degrading of their jobs because workload has increased whereas valuable resources have become scarcer (Sverke and Hellgren, 2002). Sverke and Hellgren (2002: 30) refer to qualitative job insecurity as 'perceptions of potential loss of quality in the employment relationship, such as deterioration of working conditions, demotion, lack of career opportunities, decreasing salary development, and concerns about person-organization fit in the future'. In an era were precarious work can no longer be equated to contract type (e.g. temporary work) or the prospect of unemployment, insight into the consequences of job erosion or qualitative job insecurity is gaining in importance (Lewchuk et al., 2008; Vives et al., 2013).

Previous research showed that qualitative job insecurity can undermine individual well-being (e.g. De Witte et al., 2010; Hellgren et al., 1999) and organizational attitudes such as commitment with the organization or workplace (e.g. Ashford et al., 1989; Reisel and Banai, 2002). However, little is known about the effects of qualitative job insecurity on job performance including productive behaviours such as core-task performance and organizational citizenship behaviour (OCB). Relationships with these productive behaviours may be less clear-cut for two reasons. First, as suggested by Staufenbiel and König (2010), a stressor like qualitative job insecurity may be simultaneously associated with less (i.e. hindrance effect) and more (i.e. challenge effect) job performance. On the one hand qualitative job insecurity may undermine productive behaviours since it wears out an individual's energy and psychological resources; on the other hand it may also trigger these behaviours since individuals may rely on behavioural efforts in an attempt to overcome the stressor and gain more qualitative job security. In this article we focus on the relationship with one behavioural outcome in particular: OCB. Whereas relationships with overall job performance (Ashford et al., 1989; Chirumbolo and Areni, 2010) and counterproductive behaviours directed to the organization or co-workers (e.g. Ashford et al., 1989; De Witte et al., 2010; Van den Broeck et al., 2013) have been investigated, the particular link with OCB remains to our knowledge empirically unexplored. OCB is an important outcome since extra-role behaviour impacts overall organizational effectiveness (Podsakoff et al., 2000). Furthermore, the literature on OCB makes a clear separation between intrinsic motives and instrumental motives for OCB (Bolino, 1999) that align with the underlying dynamic of the hindrance and challenge effects. Second, although there seems to be a large consensus on qualitative job insecurity's role as a stressor, it is unlikely that these effects are universal (Lazarus and Folkman, 1984). The relative weight of these hindrance and challenge effects may also depend on individual characteristics (Gilboa et al., 2008; Webster et al., 2011). Hence, in this article, we empirically unravel these presumed opposite effects and explore the role of one 'confounding' individual characteristic: chronological age. Thereby we contribute to the ongoing debate in the job insecurity literature on whether and when job insecurity could have positive effects (Borg and Elizur, 1992; De Witte, 1999; Van Vuuren et al., 1991). 
Following insights from stress research, challenge and hindrance appraisals are not necessarily mutually exclusive (Lazarus and Folkman, 1984): individuals may appraise a situation as simultaneously being a challenge and a hindrance. If a third (i.e. suppressor) variable is not being accounted for, these counteracting hindrance and challenge effects are likely to cancel each other out - unwittingly suggesting none or just a weak overall relationship (Webster et al., 2011; Widmer et al., 2012). We therefore add an intermediate variable to the qualitative job insecurity-OCB relationship, namely basic need satisfaction. We presume that basic need satisfaction may capture the hindrance effect. Basic need satisfaction is a central concept in self-determination theory (SDT) and refers to an important aspect of eudaemonic work-related well-being: feeling autonomous, competent and related (Ryan and Deci, 2000a). We assume that qualitative job insecurity may pose a threat to an individual's sense of eudaemonic well-being, thereby undermining his/her genuine tendency to display OCB. After accounting for this presumed hindrance effect via basic need satisfaction, we expect a remaining positive path from qualitative job insecurity to OCB reflecting the challenge effect. This challenge effect resembles the more active, problem-focused response to the experience of qualitative job insecurity: the intentional and goal-directed display of OCB in trying to achieve more qualitative job security (e.g. Staufenbiel and König, 2010).

In addition, in line with others (Lazarus and Folkman, 1984; Webster et al., 2011), we expect individual differences regarding the dominance of the hindrance and challenge role of qualitative job insecurity. In this article we focus on chronological age as a moderator for two reasons. First, lifespan theory suggests that the experience of insecurity and how individuals respond to it varies strongly throughout adulthood (Ebner et al., 2006; Heckhausen et al., 2010; Staudinger et al., 1995). Second, chronological age is a crucial variable in a greying labour market as organizations will have to rely more strongly on the contributions of mature age workers (de Lange et al., 2010; Porcellato et al., 2010). As this contingent of workers is rapidly growing, we need to enhance our understanding of how stressors in the work environment impact their job performance (Shirom et al., 2008; Truxillo et al., 2012).

To investigate and compare the above relationships across the lifespan, we conducted multi-group path analysis among mature age workers (i.e. aged 50 or older), prime age workers (i.e. aged 31-49 years) and young workers (i.e. aged 18-30 years).

\section{Theory and hypotheses}

\section{Qualitative job insecurity: Hindrance, challenge or both}

Qualitative job insecurity is considered to be a work stressor (Ashford et al., 1989; Laine et al., 2009; Sverke and Hellgren, 2002). Prior studies have consistently found negative associations with individual well-being (De Witte et al., 2010; Hellgren et al., 1999) and organizational attitudes such as organizational commitment (Ashford et al., 1989; Reisel and Banai, 2002), trust in the organization (Ashford et al., 1989), turnover intention (Ashford et al., 1989; Hellgren et al., 1999), work commitment (Ashford et al., 1989; Roskies and Louis-Guerin, 1990), job involvement (Otto et al., 2011) and the intention to abandon one's profession (Laine et al., 2009). Yet, with regard to 
employee performance, our knowledge remains limited. The few studies in this area focus on overall job performance or counterproductive behaviours and report inconsistent findings. Whereas Chirumbolo and Areni (2010) report a negative relationship with overall job performance, Ashford et al. (1989) find no relationship. Regarding counterproductive employee behaviours directed to the organization De Witte et al. (2010) find no association between qualitative job insecurity and absenteeism. However, Van den Broeck et al. (2013), find that qualitative job insecurity is positively associated with counterproductive behaviours such as being late at work or dragging out of time. They also note that qualitative job insecurity is positively related to counterproductive behaviours directed to co-workers such as being rude towards someone at work. To our knowledge, no previous research has focused explicitly on the relationship between qualitative job insecurity and OCB. OCB can be defined as extra-role behaviours contributing to overall organizational effectiveness that is not part of an employee's formal job description (Organ, 1988). Over the past decade, various types of OCB (e.g. helping co-workers, individual initiative) have been distinguished and its contribution to organizational effectiveness has been demonstrated (e.g. Podsakoff et al., 2000). OCB can be distinguished from core-task performance (i.e. the basic required duties of a particular job) and counterproductive performance (i.e. the intentionally engaged behaviours negatively affecting organizational effectiveness), which together with OCB encompass the broader conceptualization of job performance ( $\mathrm{Ng}$ and Feldman, 2010).

The direction of the relationship between qualitative job insecurity and job performance in general and OCB in particular may not be that clear-cut, depending on whether qualitative job insecurity is perceived as a hindrance or challenge stressor. Job hindrances are conceived as threatening obstacles draining employees' energy and interfering with their work achievement (Cavanaugh et al., 2000; Van den Broeck et al., 2010a). They can be considered as stressful demands typically perceived as beyond the control of the individual, yielding no opportunities for psychological growth. Negative emotions such as threat and anxiety prevail and individuals typically respond by adopting passive, emotion-focused coping behaviour (Crawford et al., 2010; Van den Broeck et al., 2010a; Wallace et al., 2009). By withdrawing psychologically from their job and their organization, individuals try to reduce the impact of actual losses (Dekker and Schaufeli, 1995). Therefore, if qualitative job insecurity were a hindrance, it would lead to withdrawal behaviour such as reduced OCB. This is also suggested by Davy et al. (1997) and Staufenbiel and König (2010).

In contrast, job challenges may to some degree be perceived as being manageable, even though they are highly demanding to deal with. If they can be overcome, they may hold the promise of some future gains (e.g. recognition, security) (Crawford et al., 2010; Van den Broeck et al., 2010a; Wallace et al., 2009). Therefore, if qualitative job insecurity were a challenge, it may spark positive emotions such as feelings of eagerness and confidence and elicit active, problem-focused coping behaviour such as increased OCB. Workers may increase their work effort and OCB in order to accentuate their value to the organization in an attempt to gain more job security as also suggested by Staufenbiel and König (2010) and Sverke et al. (2006).

Yet, hindrance and challenge are not necessarily mutually exclusive (Lazarus and Folkman, 1984). As an example Lazarus and Folkman (1984) refer to the appraisal of a 
job promotion. A promotion holds the potential for gains in responsibility, recognition and financial rewards. At the same time, it entails the risk of being overloaded by new demands and being unable to meet performance standards. Staufenbiel and König (2010) have argued that also qualitative job insecurity may simultaneously elicit hindrance and challenge effects. This aligns with current views and empirical findings in stress research that it might be more appropriate to conceptualize hindrance and challenge as two underlying dimensions jointly characterizing stressors, rather than two mutual exclusive categories (Gilboa et al., 2008; Lazarus and Folkman, 1984; Webster et al., 2011).

\section{Basic need satisfaction as mediator}

Since these opposite effects may suppress each other, we introduce a mediator, namely basic need satisfaction, to disentangle these presumed hindrance and challenge effects. Basic need satisfaction is a central concept in self-determination theory. SDT is a theory on human motivation positing that optimal functioning depends on the satisfaction of three universal basic psychological needs (Ryan and Deci, 2000b): (1) the need for autonomy or having a sense of volition and psychological freedom regarding one's actions and behaviours; (2) the need for relatedness or feeling connected to others; and (3) the need for competence or having an overall sense of effectiveness (Deci and Ryan, 2000). These needs are defined as 'nutriments that must be procured by a living entity to maintain its growth, integrity, and health' (Ryan and Deci, 2000a: 326). In this regard, SDT considers these needs as important conditions for eudaemonic well-being (Ryan and Deci, 2000a). SDT further assumes that these needs are highly interrelated since satisfaction of one particular need is likely to go hand in hand with satisfaction of any of the other two needs (Markland and Tobin, 2010; Van den Broeck et al., 2010b). Therefore basic needs are generally treated as manifestations of one underlying concept, i.e. basic need satisfaction (Deci and Ryan, 2000).

Basic need satisfaction may explain the hindrance effect thereby isolating it from the challenge effect. First of all, qualitative job insecurity implies a high degree of unpredictability (Hellgren et al., 1999; Sverke and Hellgren, 2002), hindering individuals in handling their situation (Lazarus and Folkman, 1984). Therefore, individuals may feel 'controlled' by their environment and this may undermine their satisfaction of the need for autonomy. In addition, feelings of autonomy may be further undermined by the fact that qualitative job insecurity is undesired. More specifically, potential losses in valued aspects may trigger negative emotions (Boya et al., 2008) causing mental distraction thereby interfering with one's work-related goals (Crawford et al., 2010). Second, qualitative job insecurity may also undermine feelings of relatedness and competence. Workers may feel being 'out of sight' (e.g. less involved in core projects or assignments) adversely affects their social bonds with supervisors (e.g. distrust, betrayal) and/or coworkers (e.g. jealousies, conflicts over scarce resources) (Ashford et al., 1989; Greenhalgh and Rosenblatt, 1984). Insecure individuals may also interpret a lack of perceived continuity as a signal that the organization is not convinced of the added value of their human capital (and the return on investments) in the long run. Feelings of being regarded as redundant may alter their overall sense of perceived competence. We therefore expect a negative relationship between qualitative job insecurity and basic need satisfaction. 
SDT has a strong theoretical and empirical basis for linking basic need satisfaction with positive employee behaviours. SDT posits that when individuals' basic needs are fulfilled, workers feel more engaged and will deploy favourable, productive behaviours (Deci and Ryan, 2000; Gagné and Deci, 2005; Wallace et al., 2009) including OCB (Greguras and Diefendorff, 2010). More specifically, individuals then experience stimulation to actively engage in subsequent need-fulfilling activities because of their intrinsic value (Deci and Ryan, 2000). Helping co-workers, taking initiative, performing beyond normal expectations may provide opportunities for additional satisfaction of the need for relatedness, autonomy and competence, respectively. Additional need satisfaction will in turn spark more positive employee behaviours. In this regard the display of OCB is regulated by intrinsic motives. This regulation mechanism relates closely to one of the two main sets of motives underlying OCB as outlined by Bolino (1999): namely the display of OCB for intrinsic motives or one's genuine desire to help others. In contrast, when basic needs are frustrated, a negative spiral is precipitated. Individuals may instead develop defences or need substitutes (Deci and Ryan, 2000), which may decrease their overall functioning and thereby also result in lower levels of OCB (Greguras and Diefendorff, 2010).

Following the above reasoning, we thus hypothesize that basic need satisfaction mediates the hindrance effect of qualitative job insecurity. When situations are regarded as hindering they are likely to thwart individuals' basic needs. In turn, this motivation depleting effect may explain why individuals' genuine intrinsic desire to help the organization or others is low, resulting in lower levels of OCB. The role of basic need satisfaction in explaining negative relationships between work stressors including qualitative job insecurity and work-related outcomes such as counterproductive behaviours has already been empirically established by others (De Cooman et al., 2013; Van den Broeck et al., 2008, 2013; Vander Elst et al., 2012). We thus hypothesize:

H1: Basic need satisfaction will mediate the negative relationship between qualitative job insecurity and OCB (i.e. hindrance effect).

As argued earlier, we assume that there may also be an additional positive relationship between qualitative job insecurity and OCB reflecting the challenging nature of qualitative job insecurity. More specifically, regardless of its relationship with basic need satisfaction, qualitative job insecurity may immediately call upon individuals to increase control over their job insecure situation. Some earlier empirical findings on the impact of quantitative job insecurity can be interpreted in this regard. More specifically, positive associations have been noted with regard to working hours (De Cuyper et al., 2008a) and job performance (Staufenbiel and König, 2010). In addition, Probst et al. (2007) found fewer counterproductive behaviours among individuals worrying about job loss, indicating that employees try to avoid any behaviour that would increase the likelihood of losing their jobs. Such efforts may encompass impression management strategies aimed at creating favourable images in the eye of their employer (Bolino, 1999; Schnake, 1991). In this regard, the display of OCB is not regulated by the fulfilment of conditions for eudaemonic well-being (i.e. basic need satisfaction) (Ryan and Deci, 2000a) but directly instrumental in achieving more qualitative job security: i.e. serving one's own interests. 
This aligns with the other, second set of motives steering OCB, namely instrumental reasons (Bolino, 1999). Hence, in response to qualitative job insecurity, intrinsically motivated OCB is expected to decrease whereas instrumentally motivated OCB is expected to increase. Since a mix of both motives may blur or suppress an overall relationship, we presume the challenge effect will show itself in a remaining direct path from qualitative job insecurity to OCB, after we accounted for the hindrance effect.

To empirically disentangle the proposed hindrance from the challenge effect of qualitative job insecurity, we follow the recommendations of Staufenbiel and König (2010). They propose comparing a full mediation model with a partial mediation model in which an additional direct path between the stressor and OCB is allowed. ${ }^{1}$ Whereas the first captures the hindrance effect, the latter models the additional positive challenge effect. Applied to our research design, we therefore hypothesize the following:

H2: A partial mediation model in which an additional direct positive relationship is allowed between qualitative job insecurity and OCB (i.e. challenge effect) will fit the data better than a full mediation model.

\section{The moderating role of age}

The relative weight of these hindrance and challenge effects may also be dependent on individual characteristics (Gilboa et al., 2008; Webster et al., 2011). Individuals may interpret situations or cope with imposed demands differently (Lazarus and Folkman, 1984). We assume that age may be an important moderator of these relationships, as has also been noted with regard to other work stressors (Matthews et al., 2010; Truxillo et al., 2012). In what follows we argue that the relative weight of the hindrance effect may be more outspoken among older workers whereas the relative weight of the challenge effect may be more pronounced among younger workers.

Lifespan development psychology puts forward that throughout the lifespan, the ratio of gains to losses in internal and external resources becomes more and more unfavourable (Baltes, 1987). Constraints in cognitive and physical resources that may otherwise help dealing with stressors, may account for more severe hindrance effects (e.g. Jex et al., 2007; Shirom et al., 2008). But, moreover, in trying to adapt to declines in health, physical and some important mental capabilities, a shift from being overly promotionfocused in younger age towards more prevention-focused in older age is posited (e.g. de Lange et al., 2010; Ebner et al., 2006; Staudinger et al., 1995). Whereas holding a promotion-focus implies one is directed towards growth (i.e. achieving gains and avoiding non-gains), holding a prevention-focus implies one is security-oriented (i.e. achieving non-losses and avoiding losses) (Higgins, 1997; Molden et al., 2008). We assume that qualitative job insecurity is likely to be more hindering among older, security-oriented individuals for two reasons. First, the prospect of potential losses may be more undesirable for this group as it conflicts more strongly with their focal concern on loss avoidance. Second, the negative affect associated with perceived losses is expected to be stronger among prevention-focused individuals. Whereas perceived threats will 'only' trigger low arousal affect (i.e. sadness) among promotion-focused individuals, they are assumed to trigger high arousal affect (i.e. anxiety) among prevention-focused individuals 
(e.g. Molden et al., 2008). Higher levels of negative arousal may distract individuals from the satisfaction of their basic needs (e.g. Crawford et al., 2010). This reasoning also aligns with the finding from Cheng and Chan's (2008) meta-analysis that the quantitative dimension of job insecurity is more negatively related to psychological well-being at older age. Hence, as chronological age is associated with holding a stronger preventionfocus, the hindrance effect of qualitative job insecurity may be more outspoken among older workers. We therefore hypothesize:

H3: The relationship between qualitative job insecurity and basic need satisfaction will be moderated by age such that this negative relationship is stronger at older age.

As argued earlier, the additional positive, direct path between qualitative job insecurity and OCB is likely to reflect the challenging nature of qualitative job insecurity. However, given a stronger prevention-focus at older age, mature age workers may be less susceptible to recognize the challenging aspect of qualitative job insecurity: i.e. its opportunities for future gains. In addition to differences in appraisal, reliance on problem-focused coping behaviour to alter undesired situations may also wane at older age. Problemfocused coping behaviour is highly resource costly (Shimazu and Schaufeli, 2007). And in the face of resource constraints at older age, lifespan theory of control (Heckhausen and Schulz, 1995) suggests that instead of relying on active, behavioural oriented control strategies (i.e. primary control) such as increased effort, older individuals will rely more on active, but less resource costly cognitive control strategies (i.e. secondary control) such as boosting the value of the goal (Brandtstädter and Renner, 1990; Heckhausen, 1997). As a consequence, when confronted with an undesired situation such as qualitative job insecurity, the likelihood that individuals will rely on investments of behavioural resources (i.e. OCB) to gain more security is likely to decrease with chronological age. We therefore hypothesize:

H4: The additional direct relationship between qualitative job insecurity and OCB will be moderated by age such that this positive relationship is weaker at older age.

Since ageing unfolds gradually throughout the lifespan, we will test our hypotheses by making pairwise comparisons between mature age, prime age and young workers assuming that neighbouring age groups will be more alike compared to more distal ones.

\section{Method}

\section{Participants}

We use data from a web-based survey enrolled in April and May 2009 among Belgian (Dutch speaking) employees. A large-scale media campaign (e.g. through job advertisement magazines and newspapers) was set up to draw attention to the questionnaire (provided online). To enhance participation, we awarded an iPhone to a randomly selected respondent. After deletion of incomplete records and exclusion of entrepreneurs, job 
Table I. Distribution of sample characteristics across age groups.

\begin{tabular}{|c|c|c|c|}
\hline & Age I8-30 $(n=1243)$ & Age $31-49(n=1786)$ & Age $50+(n=214)$ \\
\hline & $\%$ & $\%$ & $\%$ \\
\hline \multicolumn{4}{|l|}{ I. Gender } \\
\hline Male & 54.3 & 57.6 & 66.7 \\
\hline Female & 45.7 & 42.4 & 33.3 \\
\hline \multicolumn{4}{|l|}{ 2. Job level } \\
\hline Senior management & 1.0 & 8.1 & 15.0 \\
\hline Middle management & 13.6 & 34.7 & 35.8 \\
\hline Professional staff & 34.0 & 30.9 & 22.5 \\
\hline $\begin{array}{l}\text { Manual and operative } \\
\text { workers }\end{array}$ & 39.0 & 18.6 & 19.2 \\
\hline Clerical workers & 12.4 & 7.7 & 7.5 \\
\hline \multicolumn{4}{|l|}{ 3. Education } \\
\hline $\begin{array}{l}\text { No higher education } \\
\text { degree }\end{array}$ & 17.8 & 21.8 & 22.1 \\
\hline \multirow{2}{*}{$\begin{array}{l}\text { Higher education } \\
\text { degree }\end{array}$} & 82.2 & 78.2 & 77.9 \\
\hline & $M$ (in months) & $M$ (in months) & $M$ (in months) \\
\hline 5. Job tenure & 26.8 & 61.3 & $|20|$. \\
\hline $\begin{array}{l}\text { 6. Organizational } \\
\text { tenure }\end{array}$ & 29.1 & 83.9 & 155.9 \\
\hline
\end{tabular}

students, temporary workers and workers employed by an employment agency, we have data from 3243 employees with a permanent contract. We left out temporary workers since their perceptions of future job conditions are highly different (i.e. predictable) due to the finite nature of their employment contract (De Cuyper et al., 2008b). Our sample consists of workers aged 18-64 with an average age of about 35 years. About $57 \%$ of our sample is male and about $80 \%$ had obtained a bachelor's or master's degree. Concerning job level, our sample consists of manual and operative workers (26\%), clerical workers (9\%), professional staff members (32\%), line managers (27\%) and senior managers $(6 \%)$. The average length of service with their current employer was about 68 months. In total 1243 workers are aged 18-30 (i.e. young workers), 1786 are aged 31-49 (i.e. prime age workers) and 214 are aged 50 or older (i.e. mature age workers). Differences in sample size between the age groups are not troublesome, more important is that the sample size within each group is large enough to have enough statistical power $(N>100)$ (e.g. Bing et al., 2007). Sample characteristics for the three age groups are provided in Table 1 in more detail.

\section{Measures}

Qualitative job insecurity is measured using the four-item scale of Hellgren et al. (1999). Following recommendations of Davy et al. (1997) and Lim (1997), the items of the scale 
express perceived continuity regarding the quality of the present employment relationship such as for instance skill utilization ('I believe that the organization will need my competence also in the future'). All items are rated on a five-point Likert scale from 1 (totally disagree) to 5 (totally agree) and are reverse coded so higher scores express higher levels of qualitative job insecurity.

Basic need satisfaction is measured using the three satisfaction subscales from the Basic Need Satisfaction at Work Scale of Van den Broeck et al. (2010b): capturing the extent to which the need for competence (three items: e.g. 'I am good at the things I do in my job'), autonomy (three items: e.g. 'I feel I can be myself at my job') and relatedness (three items: e.g. 'Some people I work with are close friends of mine') are satisfied. All items are assessed on a five-point Likert scale ranging from 1 (totally disagree) to 5 (totally agree).

$O C B$ is assessed by the scale of Moorman and Blakely (1995). The scale measures individual initiative (three items: e.g. 'I frequently communicate suggestions to co-workers on how our team or department could improve its functioning'), interpersonal helping (three items: e.g. 'I try to help co-workers with work-related problems') and personal industry (three items: e.g. 'I perform my duties with unusually few errors'). Individual initiative refers to communications to others in the workplace to improve individual and group performance. Interpersonal helping refers to helping co-workers in their jobs when such help is needed. Finally, personal industry concerns task performance above and beyond normal role expectations. All items are measured on a five-point Likert scale from 1 (totally disagree) to 5 (totally agree).

Finally, we include job level, gender and educational level as control variables. All control variables are measured as dummy variables. Job level comprises senior management, middle management, professional staff members (reference category), manual and operative workers and clerical workers. For gender, the reference category is 'male'. Concerning educational level, we distinguish between having a higher education degree (bachelor's or master's degree) versus no higher education degree (reference category).

\section{Results}

\section{Preliminary results}

For the analyses, we used Mplus version 5.2 with maximum likelihood estimation of the raw data (Muthén and Muthén, 1998-2012). Before testing the hypotheses we investigate the measurement model in several steps following recommendations of Byrne et al. (1989). The hypothesized measurement model comprises the expected latent variables of qualitative job insecurity, basic need satisfaction and OCB. Concerning OCB, the latent variables individual initiative, interpersonal helping and personal industry are operationalized by their items and load additionally on a second order factor OCB. This approach fits the view that separate dimensions of OCB are best viewed as indicators of a general OCB factor (Hoffman et al., 2007). In a similar vein and in line with theory and other empirical studies (e.g. Van den Broeck et al., 2008; Wei et al., 2005), the need for autonomy, relatedness and competence - operationalized by their items - load additionally on a higher order factor, namely basic need satisfaction. 


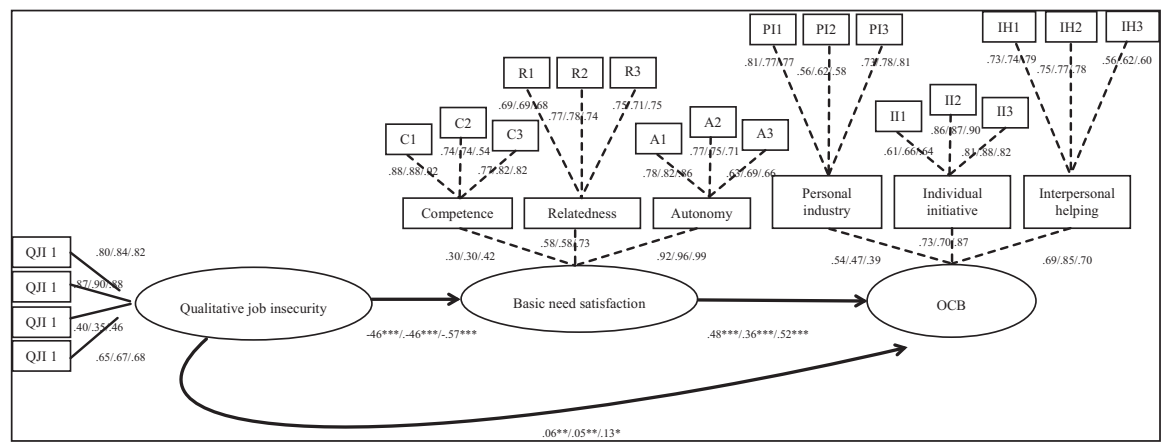

Figure I. Results of the hypothesized measurement and structural path model. Standardized factor loadings (all $p<.00 \mathrm{I}$ in step I).

Standardized structural coefficients $\left({ }^{*} p<.1 ; * * p<.05 ; * * * p<.001\right.$ in step 2$)$.

We first fit the measurement model in each age group separately. The model fit is evaluated using four goodness of fit indices: the comparative fit index (CFI), the Tucker Lewis Index (TLI), ${ }^{2}$ the root mean square error of approximation (RMSEA) and the standardized root mean square residuals (SRMR) (Hu and Bentler, 1999). Our results indicate acceptable model fit for young $\left(\chi_{(200)}^{2}=1280.08, p<.001 ; \mathrm{CFI}=.90, \mathrm{TLI}=.88\right.$, $\mathrm{RMSEA}=.07$ and SRMR $=.09)$, prime age $\left(\chi^{2}{ }_{(200)}=1329.23, p<.001 ; \mathrm{CFI}=.93\right.$, TLI $=.92, \mathrm{RMSEA}=.06$ and SRMR $=.08)$ and mature age workers $\left(\chi_{(200)}^{2}=432.37, p<\right.$ $.001 ; \mathrm{CFI}=.89, \mathrm{TLI}=.87, \mathrm{RMSEA}=.07$ and SRMR $=.09$ ).

Subsequently, we use multi-group confirmatory factor analysis (CFA) to establish configural invariance and invariance in factor loadings across the three age groups. First, the fit of the measurement model with all factor loadings varying across groups is satisfactory $\left(\chi_{(600)}^{2}=3041.69, p<.001 ; \mathrm{CFI}=.92, \mathrm{TLI}=.90, \mathrm{RMSEA}=.06\right.$ and SRMR $=$ $.08)$, providing an indication of configural invariance. All indicators obtain highly significant factor loadings on their latent variables $(p<.001)$ as depicted in Figure 1. Second, we compare the chi-square statistic of this model with that of a more constrained model in which all factor loadings are set equal across groups. The fit of this constrained model $\left(\chi_{(630)}^{2}=3084.16, p<.001 ; \mathrm{CFI}=.91, \mathrm{TLI}=.91, \mathrm{RMSEA}=.06\right.$ and $\left.\mathrm{SRMR}=.09\right)$ is not significantly worse $\left(\Delta \chi_{(30)}^{2}=42.47, \mathrm{~ns}\right)$, suggesting invariance in factor loadings across age groups.

Finally, we compare the fit of the hypothesized measurement model with sensible alternative models. First, in line with the recommendations of Podsakoff et al. (2003) to test for common method variance, we test a one-factor model in which all items load on one common factor. The model fit is significantly worse than the fit of the hypothesized measurement model $\left(\chi_{(627)}^{2}=18,747.10, p<.001 ; \mathrm{CFI}=.37, \mathrm{TLI}=.30, \mathrm{RMSEA}=.16\right.$ and $\left.\mathrm{SRMR}=.14 ; \Delta \chi_{(27)}^{2}=15,705.41, p<.001\right)$. Next, we test three more plausible models by collapsing pairwise constructs of our measurement model. A model in which qualitative job insecurity and basic need satisfaction form an additional factor fits significantly worse compared to our hypothesized measurement model $\left(\chi_{(603)}^{2}=3074.37, p<.001\right.$; $\mathrm{CFI}=.91, \mathrm{TLI}=.90, \mathrm{RMSEA}=.06$ and SRMR $\left.=.09 ; \Delta \chi_{(3)}^{2}=32.68, p<.001\right)$. In a 
Table 2. Means, standard deviations, Cronbach's alphas and correlations across age groups.

\begin{tabular}{lllllll}
\hline Age I8-30 & $M$ & SD & $\alpha$ & 1 & 2 & 3 \\
\hline I. Qualitative job insecurity & 2.90 & .81 & .78 & - & \\
2. Basic need satisfaction & 3.62 & .55 & .77 & $-.46^{* *}$ & - \\
3. OCB & 3.85 & .48 & .78 & $-.17^{* *}$ & $.46 * *$ & - \\
\hline Age 3I-49 & $M$ & SD & $\alpha$ & 1 & 2 & 3 \\
\hline I. Qualitative job insecurity & 2.98 & .81 & .78 & - & & - \\
2. Basic need satisfaction & 3.67 & .55 & .78 & $-.44^{* *}$ & - & \\
3. OCB & 4.01 & .47 & .81 & $-.13^{* *}$ & $.35^{* *}$ & - \\
\hline Age 50 + & $M$ & SD & $\alpha$ & 1 & 2 & 3 \\
\hline I. Qualitative job insecurity & 3.10 & .82 & .78 & - & & \\
2. Basic need satisfaction & 3.65 & .61 & .81 & $-.57^{* *}$ & - & $.43^{* *}$ \\
3. OCB & 4.07 & .42 & .78 & $-.12^{*}$ & - \\
\hline
\end{tabular}

$*_{p}<.05 ; * * p<.01$.

similar vein, collapsing need satisfaction and OCB results in a significantly worse model fit $\left(\chi_{(606)}^{2}=3967.29, p<.001 ; \mathrm{CFI}=.88, \mathrm{TLI}=.87, \mathrm{RMSEA}=.07\right.$ and $\mathrm{SRMR}=.10 ; \Delta$ $\left.\chi_{(6)}^{2}=925.60, p<.001\right)$, as well as collapsing qualitative job insecurity and OCB $\left(\chi_{(603)}^{2}\right.$ $=3913.01, p<.001 ; \mathrm{CFI}=.88, \mathrm{TLI}=.87, \mathrm{RMSEA}=.07$ and $\mathrm{SRMR}=.10 ; \Delta \chi_{(3)}^{2}=$ $871.32, p<.001)$.

Since these alternative models have a worse fit than our hypothesized measurement model and since both invariance requirements of our hypothesized measurement model are met, meaningful comparisons concerning structural relationships across age groups can be made in a next step. Scale information and correlations are provided in Table 2 for each age group separately.

Before going to our structural model, we additionally test whether the dependent variable in our model (i.e. OCB) differs as a function of educational level, gender and job level. Independent samples $t$-testing reveals that having a higher education degree is unrelated to $\mathrm{OCB}\left(t_{(3430)}=1.57, \mathrm{~ns}\right)$ but gender makes a difference: women report more OCB compared to men $\left(t_{(3430)}=-2.86, p<.005\right)$. In addition, a one-way ANOVA shows that OCB levels differ as a function of job level $\left(F_{(4,3427)}=34.37, p<.001\right)$. Employees in lower level jobs report less OCB compared to employees in higher level jobs. Based on these preliminary analyses, we decide to add direct paths to OCB for both gender (reference category $=$ male) and job level (four dummies: manual and operative workers, clerical workers, line managers and senior managers; reference category = professional staff members) in our structural model.

\section{Hypothesis testing}

We conduct multi-group path analysis following the two-step approach as suggested by McDonald and Ho (2002) and McDonald (2010): i.e. examining the fit of our hypothesized path model and our measurement model separately. First, we test the hypothesized 
full mediation model in all age groups. The model fit is $\operatorname{good}\left(\chi_{(18)}^{2}=34.67, p<.1\right.$; CFI $=.99, \mathrm{TLI}=.98, \mathrm{RMSEA}=.03$ and $\mathrm{SRMR}=.01)$. Subsequently, we compare this model with a partial mediating model in which an additional direct path between qualitative job insecurity and OCB is specified across all age groups. The results indicate that adding a direct path to OCB improves model fit significantly $\left(\chi_{(15)}^{2}=22.58, p<.1\right.$; CFI $=.99$, TLI $=.99, \operatorname{RMSEA}=.02$ and $\left.\mathrm{SRMR}=.01 ; \Delta \chi_{(3)}^{2}=12.09, p<.01\right)$.

As expected, standardized path coefficients of the partial mediation model indicate that qualitative job insecurity relates negatively to basic need satisfaction for young $(\beta=-.46, p$ $<.001)$, prime age $(\beta=-.45, p<.001)$ and mature age workers $(\beta=-.57, p<.001)$. In turn, basic need satisfaction relates positively to OCB for young $(\beta=.48, p<.001)$, prime age $(\beta$ $=.36, p<.001)$ and mature age workers $(\beta=.52, p<.001)$. Finally, a direct path between qualitative job insecurity and OCB is significant - and as expected - positive across all age groups $\left(\beta=.06, p<.05 ; \beta=.05, p<.05 ; \beta=.13, p<.1\right.$ respectively $^{3}$ ) (see Figure 1 ).

The indirect (i.e. hindrance) effect of qualitative job insecurity on OCB through basic need satisfaction is significant $(p<.001)$ across all age groups $(-.22,-.16,-.30$ respectively). As expected, the total effects of qualitative job insecurity on OCB (-.16, -.11, -.16 respectively) are smaller than the indirect effect due to the significance of a remaining, positive (i.e. challenge) direct effect between qualitative job insecurity and OCB. Thus, substantial support is provided for hypotheses 1 and 2 .

To explicitly test our moderation hypotheses 3 and 4, we compare the partial mediation model obtained in the last step (M0) with a series of more restricted models in which one of the structural relationships is constrained to be equal across two age groups. Results are depicted in detail in Table 3. First, imposing equality of the structural coefficient between qualitative job insecurity and basic need satisfaction for young and mature age workers $\left(\mathrm{M} 1 \mathrm{a}: \Delta \chi_{(1)}^{2}=5.76, p<.05\right)$; and for prime age and mature age workers (M1b: $\Delta \chi_{(1)}=$ $6.91, p<.01)$, results in a significant decrease of model fit. The structural coefficient for young and prime age workers does not differ however. Overall support is provided for hypothesis 3 that qualitative job insecurity is more negatively related to basic need satisfaction at older age. Second, the structural coefficients of the direct path between qualitative job insecurity and OCB do not differ across age groups. None of the pairwise comparisons $(\mathrm{M} 2 \mathrm{a}-\mathrm{c})$ result in a significant lower model fit. These findings do not support hypothesis 4 .

Regarding the control variable 'job level', we find no differences among the youngest age group. However, in both prime age and mature age samples senior $(\beta=.14, p<.001$; $\beta=.17, p<.05)$ and line managers $(\beta=.17, p<.05 ; \beta=.19, p<.05)$ report more OCB. In addition, also mature age clerical workers report more $\mathrm{OCB}(\beta=.19, p<.01)$. All these differences are relative, i.e. compared to professional staff members. Concerning gender, we find that women report more OCB compared to men among both young age $(\beta=.06, p<.05)$ and prime age $(\beta=.09, p<.001)$ workers. No significant relationship is noted among mature age workers.

\section{Discussion}

\section{Theoretical implications}

We draw attention to the importance of the often overlooked qualitative dimension of job insecurity. Most interest within the job insecurity literature has gone to understanding the 
Table 3. Goodness of fit indices of the moderation models.

\begin{tabular}{llllllllll}
\hline Model & $\chi^{2}$ & df & CFI & TLI & RMSEA SRMR & $\begin{array}{l}\text { Model } \\
\text { comparison }\end{array}$ & $\Delta \chi^{2}$ & $\Delta d f$ \\
\hline
\end{tabular}

Structural relationships estimated freely

$\begin{array}{lllllllll}\text { M0 } & 22.58 & 15 & .99 & .99 & .02 & .01 & /\end{array}$

Equality constraint of the path of qualitative job insecurity to basic need satisfaction

$\begin{array}{llllllllll}\text { Mla: Young-Mature age } & 28.34 & 16 & .99 & .98 & .03 & .02 & \text { Mla-M0 } & 5.76^{*} & \text { I } \\ \text { MIb: Prime-Mature age } & 29.49 & 16 & .99 & .98 & .03 & .02 & \text { Mlb-M0 } & 6.91^{* *} & \text { । } \\ \text { MIc: Young-Prime age } & 22.70 & 16 & .99 & .99 & .02 & .01 & \text { Mlc-M0 } & .12 & \text { । }\end{array}$

$\begin{array}{llllllllll}\text { Mlc: Young- Prime age } & 22.70 & 16 & .99 & .99 & .02 & .01 & \text { Mlc-M0 } & .12 & \text { I }\end{array}$

Equality constraint of the path of qualitative job insecurity to $O C B$

$\begin{array}{llllllllll}\text { M2a: Young-Mature age } & 23.15 & 16 & .99 & .99 & .02 & .01 & \text { M2a-M0 } & .57 & \text { I } \\ \text { M2b: Prime-Mature age } & 23.55 & 16 & .99 & .99 & .02 & .01 & \text { M2b-M0 } & .97 & \text { I } \\ \text { M2c: Young- Prime age } & 22.7 \mathrm{I} & 16 & .99 & .99 & .02 & .01 & \text { M2c-M0 } & .13 & \text { I }\end{array}$

$*_{p}<.05 ; * * p<.01$.

consequences of quantitative job insecurity (e.g. Cheng and Chan, 2008; Sverke and Hellgren, 2002; Vander Elst et al., 2012). The scarce research on the consequences of qualitative job insecurity mainly looked at the impact on well-being and organizational attitudes. The very few studies focusing on employee behaviours focused on either overall job performance or counterproductive behaviours. We extended previous research by focusing on a particular type of employee behaviour, i.e. OCB.

This broadening has also theoretical importance. From a theoretical point of view, qualitative job insecurity may behave as a hindrance, impeding OCB, and a challenge stressor, triggering OCB. These counteracting effects may cancel each other out, unwittingly suggesting none or just a weak overall relationship with OCB. We thereby also touch upon the broader debate on the positive/negative behavioural effects of job insecurity in general.

We believe this article makes two valuable contributions to this debate. First, by introducing the concept of basic need satisfaction, we were able to show that the overall effect of qualitative job insecurity on OCB comprises both a hindrance and challenge effect. These findings align with recent views in stress research conceptualizing hindrance and challenge as two underlying dimensions jointly characterizing stressors (e.g. Webster et al., 2011). More specifically, our results reveal that qualitative job insecurity lowers OCB through its negative impact on basic need satisfaction. This negative indirect effect indicates that qualitative job insecurity undermines one's sense of autonomy, competence and relatedness thereby decreasing one's propensity to 'freely' engage in OCB. This hindrance effect is noted across all age groups. As expected, we find a remaining direct relationship between qualitative job insecurity and OCB across all age groups, although weaker in magnitude. This response can be interpreted as individual efforts directed to gaining control over qualitative job insecurity: i.e. by 'looking' dedicated. The motives underlying the hindrance and challenge effect align with Bolino's (1999) distinction between intrinsic motives and instrumental motives for OCB. Overall our results reveal that qualitative job insecurity acts as a hindrance and challenge stressor but that the hindrance effect downplays the challenge effect across all age groups as indicated by the negative sign of the total 
effects. In other words: qualitative job insecurity undermines intrinsically motivated OCB more than it stimulates extrinsically or instrumentally motivated OCB.

Our approach, i.e. relying on basic need satisfaction (i.e. as indicator of eudaemonic well-being), differs from Staufenbiel and König's (2010) approach focusing on the mediating role of hedonic well-being as operationalized by work attitudes (i.e. job satisfaction, organizational commitment). We argue that the disentanglement of the challenge and hindrance effect on OCB using basic need satisfaction may be more clear-cut than if we had relied on work-related attitudes. Basic need satisfaction may account for the intrinsic reasons underlying OCB, so the direct path to OCB is likely to reflect instrumental reasons. Moreover, as pointed out by Leary and Kowalski (1990), those wanting to look dedicated (i.e. impress) may also be strongly committed to their organizations. Therefore, using organizational commitment or job satisfaction as a mediator may tend to mix up both sets of motives.

Second, this study is - to our knowledge - the first on the consequences of qualitative job insecurity for employee behaviour that explicitly investigates age-related differences. More specifically, we explore the relative weight of these hindrance and challenge effects across different age groups. In line with our hypotheses, we found that the hindrance effect of qualitative job insecurity is stronger among mature age workers. This finding is in accordance with lifespan theory (e.g. Ebner et al., 2006; Staudinger et al., 1995) suggesting that at older age individuals experience the prospect of perceived losses as more upsetting. This finding also aligns with Cheng and Chan's (2008) conclusion that quantitative job insecurity is more negatively related to psychological well-being at older age. However, the challenge effect did not differ across age groups. One explanation is that the challenge effect we posited assumes that workers are - at least to some extent - seeking to alter their poor work prospects within the current employer-employee relationship. Yet, young age workers may perceive more external alternatives in the labour market compared to mature age workers (Berntson et al., 2006; Rothwell and Arnold, 2007). This difference in 'job dependence' (e.g. Cheng and Chan, 2008) may counteract with the effects we hypothesized. More specifically, whereas older workers may depend more heavily on their current employer-relationship, to do something about their dead-end career job, younger workers may seek qualitative job security elsewhere and therefore refrain from trying to reverse the odds in their organization. Overall the age-related findings suggest that qualitative job insecurity is more strongly associated with OCB for mature age workers. Whereas the magnitude of the challenge effect is similar across age groups, the hindrance effect is more prominent among workers aged 50 or older.

\section{Practical implications}

First of all, our results show that qualitative job insecurity is more a hindrance than a challenge stressor. Even though qualitative job insecurity may trigger OCB, problem-focused coping remains highly resource costly (e.g. Shimazu and Schaufeli, 2007) risking a state of resource exhaustion if the goal remains unachievable (Hobfoll, 1989). In addition, instrumentally motivated OCB may also be of lesser quality and may therefore not necessarily contribute to organizational effectiveness (Bolino et al., 2004). Hence, the strategic use of insecurity to foster favourable productive employee behaviours on the work 
floor (e.g. Borg and Elizur, 1992) is not supported by our findings. Instead, for the purpose of increasing organizational effectiveness, organizations should try to send unambiguous signals to their employees that they are fully engaging in the long term. This could for instance be achieved by increasing investments in HRM practices (e.g. career development, working in teams and appraisal of functioning or performance) that are aimed at eliciting high involvement by the organization (e.g. Armstrong-Stassen and Ursel, 2009). Because these practices may also explicate one's future role in the organization they may potentially reduce qualitative job insecurity. Moreover, such practices may also directly contribute to basic need satisfaction thereby counterbalancing the need-frustrating effects of qualitative job insecurity (Marescaux et al., 2013).

Second, the findings suggest that in tackling qualitative job insecurity, more attention should be directed at mature age workers. Our results indicate a stronger hindrance effect among workers aged 50 or older. The perspective of being stuck in a dead-end job may be tough to bear for older workers and may be counterproductive for their retention. Hence, successful retention of older workers may thus lie in responding to their call for being recognized for their continuing value to the organization (Kooij et al., 2011). This may demand more from organizations. On the one hand most popular age-related HRM measures are mostly directed to reducing working time and workload and lowering organizational responsibilities (Buyens et al., 2009; Van Dalen et al., 2009). Although such practices may lower exposure to other stressors (e.g. workload), if carelessly managed and communicated, they may run the risk of involuntary strengthening perceptions of potential loss of quality in the employment relationship. Our findings on qualitative job insecurity suggest that organizations should be cautious about the signals they may send out through such well-intentioned measures. On the other hand, in particular mature age workers may run the risk of receiving less feedback concerning their functioning or career development, assuming they are less interested in learning and career changes (e.g. Posthuma and Campion, 2009). By introducing regular and systematic feedback (e.g. by performance appraisals) the subtle, often unconscious and unwanted asymmetrical distribution of supervisors' time and resources can be tackled. Moreover, regular feedback (either by appraisal of functioning or performance or conversations about career development) may lower qualitative job insecurity since communication may enhance predictability in the work situation and also fosters feelings of control (Vander Elst et al., 2010).

\section{Limitations}

Although we use the common terms 'hindrance effect' and 'challenge effect', the crosssectional nature of the design implies that we cannot infer causality. Second, we rely on self-report measures. The use of self-reports may artificially inflate the strength of the observed relationships (i.e. common method bias). However, our multi-group CFA results do show that the constructs of our hypothesized model can be empirically distinguished both within and across age groups. A third critique may relate to our measurement of qualitative job insecurity. The scale of Hellgren et al. (1999) rejects the use of explicit negatively worded items such as 'fear' or 'worry', which are however considered to be part of the experience of qualitative job insecurity. Yet, such wording may explicitly suggest that qualitative job insecurity is a hindrance, i.e. a stressor triggering negative emotions (Sverke et al., 2006; Webster et al., 2010). Given our interest in 
exploring both the hindrance and challenge effect of qualitative job insecurity, the more neutral formulated items of Hellgren et al. (1999) may be a more appropriate alternative. Finally, there are some limitations concerning our use of chronological age. Although separation of age groups is common in the literature (e.g. Kooij et al., 2008), it remains normative to assume for instance that all workers over 50 are highly alike. In addition, although we expected age differences to be rooted in underlying age-related processes (e.g. prevention-/promotion-focus) we did not directly include measures of these processes. However, among policy makers chronological age remains an important way of categorizing individuals and a point of departure for targeting interventions. Also in organizations decisions about human capital investments are often made on the basis of chronological age. It is therefore important to gain insight into how different age groups will respond when organizations fail to provide a long-term perspective.

\section{Future research}

Concerning the independent variable, one avenue for research may encompass investigating other stressors such as quantitative job insecurity and comparing the relative contributions of qualitative and quantitative job insecurity in explaining OCB across age groups. Concerning the outcomes, future research may want to explore the challenge effect in more depth by including alternative strategies of primary control (e.g. working overtime and work effort). In addition, if research is driven by concerns related to a greying labour market, it would be valuable to investigate long-term consequences such as precursors of retirement (e.g. retirement planning) or actual retirement decisions among mature age workers. Finally, instead of using chronological age as a moderator, future research may want to look at other meaningful ways to operationalize age such as psychosocial age (Kooij et al., 2008). The extent to which one feels 'old' may better demarcate 'older' from 'younger' workers, overall resulting in a clearer picture with regard to the consequences of qualitative job insecurity. In addition, future research may want to explore whether chronological age effects can be attributed to, for instance, a shift in regulatory (prevention/promotion) focus by including these measures in the research design.

\section{Acknowledgements}

Our sincere thanks to Anja Van den Broeck and Tinne Vander Elst for their comments on an earlier version of the article.

\section{Funding}

This contribution was supported by funding of Research Foundation - Flanders (research project G.0086.08).

\section{Notes}

1. The model we test can be considered a suppressor model, which is analogous to a partial mediation model. The only difference with a partial mediation model is that we propose that the indirect and direct effects from the independent on the dependent variable have opposite instead of similar signs. This is also referred to as inconsistent mediation and tackled in a 
similar way as consistent mediation in which direct and indirect effects are of similar sign (MacKinnon et al., 2000).

2. TLI is an incremental fit index computed by the same formula as the non-normed fit index (NNFI) (Hu and Bentler, 1999).

3. Note that the standardized structural coefficient among the mature age group is significant at the $10 \%$ level. We regard this result as potentially relevant since sample size for that group is considerably smaller than for both other age groups. In addition, omission of this coefficient makes it impossible to formally test equality of coefficients across age groups in a next step.

\section{References}

Armstrong-Stassen M and Ursel ND (2009) Perceived organizational support, career satisfaction, and the retention of older workers. Journal of Occupational and Organizational Psychology 82(1): 210-220.

Ashford S, Lee C and Bobko P (1989) Content causes, and consequences of job insecurity: A theory-based measure and substantive test. Academy of Management Journal 32(4): $803-829$.

Baltes PB (1987) Theoretical propositions of life-span developmental psychology: On the dynamics between growth and decline. Developmental Psychology 23(5): 611-626.

Berntson E, Sverke M and Marklund S (2006) Predicting perceived employability: Human capital or labour market opportunities? Economic and Industrial Democracy 27(2): 223-244.

Bing MN, LeBreton JM, Davison HK et al. (2007) Integrating implicit and explicit social cognitions for enhanced personality assessment: A general framework for choosing measurement and statistical methods. Organizational Research Methods 10(2): 136-179.

Bolino M (1999) Citizenship and impression management: Good soldiers or good actors? Academy of Management Review 1: 82-98.

Bolino MC, Turnley WH and Niehoff BP (2004) The other side of the story: Re-examining prevailing assumptions about organizational citizenship behavior. Human Resource Management Review 14: 229-246.

Borg I and Elizur D (1992) Job insecurity: Correlates, moderators and measurement. International Journal of Manpower 13(2): 13-26.

Boya FO, Demiral Y, Ergör A et al. (2008) Effects of perceived job insecurity on perceived anxiety and depression in nurses. Industrial Health 46(6): 613-619.

Brandtstädter J and Renner GT (1990) Tenacious goal pursuit and flexible goal adjustment: Explication and age-related analysis of assimilative and accommodative strategies of coping. Psychology and Aging 5(1): 58-67.

Buyens D, Van Dijk H, Dewilde T and De Vos A (2009) The ageing workforce: Perceptions of career ending. Journal of Managerial Psychology 24(2): 102-117.

Byrne BM, Shavelson RJ and Muthén B (1989) Testing for the equivalence of factor covariance and mean structures: The issue of partial measurement invariance. Psychological Bulletin 105(3): 456-466.

Cavanaugh MA, Boswell WR, Roehling MV and Boudreau JW (2000) An empirical examination of self-reported work stress among US managers. Journal of Applied Psychology 85(1): $65-74$.

Cheng GH-L and Chan DK-S (2008) Who suffers more from job insecurity? A meta-analytic review. Applied Psychology: An International Review 57(2): 272-303.

Chirumbolo A and Areni A (2010) Job insecurity influence on job performance and mental health: Testing the moderating effect of the need for closure. Economic and Industrial Democracy 31(2): 195-214. 
Crawford ER, LePine JA and Rich BL (2010) Linking job demands and resources to employee engagement and burnout: A theoretical extension and meta-analytic test. Journal of Applied Psychology 95(5): 834-848.

Davy JA, Kinicki AJ and Scheck CL (1997) A test of job security's direct and mediated effects on withdrawal cognitions. Journal of Organizational Behavior 18(4): 323-349.

Deci EL and Ryan RM (2000) The 'what' and 'why' of goal pursuits: Human needs and the selfdetermination of behavior. Psychological Inquiry 11(4): 227-268.

De Cooman R, Stynen D, Van den Broeck A et al. (2013) How job characteristics relate to need satisfaction and autonomous motivation: Implications for work effort. Journal of Applied Social Psychology 43(6): 1342-1352.

De Cuyper N, Bernhard-Oettel C, Berntson E et al. (2008a) Employability and employees' wellbeing: Mediation by job insecurity. Applied Psychology: An International Review 57(3): 488-509.

De Cuyper N, De Jong J, De Witte H et al. (2008b) Literature review of theory and research on the psychological impact of temporary employment: Towards a conceptual model. International Journal of Management Reviews 10(1): 25-51.

Dekker WA and Schaufeli WB (1995) The effects of job insecurity on psychological health and withdrawal: A longitudinal study. Australian Psychologist 30(1): 57-63.

De Lange AH, Van Yperen NW, Van der Heijden BIJM and Bal PM (2010) Dominant achievement goals of older workers and their relations with motivation-related outcomes. Journal of Vocational Behavior 77(1): 118-125.

De Witte H (1999) Job insecurity and psychological well-being: Review of the literature and exploration of some unresolved issues. European Journal of Work and Organizational Psychology 8(2): 155-157.

De Witte H, De Cuyper N, Handaja Y et al. (2010) Associations between quantitative and qualitative job insecurity and well-being: A test in Belgian banks. International Studies of Management and Organization 40(1): 40-56.

Ebner NC, Freund AM and Baltes PB (2006) Developmental changes in personal goal orientation from young to late adulthood: From striving for gains to maintenance and prevention of losses. Psychology and Aging 21(4): 664-678.

Gagné M and Deci EL (2005) Self-determination theory and work motivation. Journal of Organizational Behavior 26(4): 331-362.

Gilboa S, Shirom A, Fried Y and Cooper CL (2008) A meta-analysis of work demand stressors and job performance: Examining main and moderating effects. Personnel Psychology 61(2): $227-271$.

Greenhalgh L and Rosenblatt Z (1984) Job Insecurity: Toward conceptual clarity. Academy of Management Review 9(3): 438-448.

Greguras GJ and Diefendorff JM (2010) Why does proactive personality predict employee life satisfaction and work behaviors? A field investigation of the mediating role of the selfconcordance model. Personnel Psychology 63(3): 539-560.

Heckhausen J (1997) Developmental regulation across adulthood: Primary and secondary control of age-related challenges. Developmental Psychology 33(1): 176-187.

Heckhausen J and Schulz R (1995) A life-span theory of control. Psychological Review 102: 284 304.

Heckhausen J, Wrosch C and Schulz R (2010) A motivational theory of life-span development. Psychological Review 117(1): 32-60.

Hellgren J, Sverke M and Isaksson K (1999) A two-dimensional approach to job insecurity: Consequences for employee attitudes and well-being. European Journal of Work and Organizational Psychology 8(2): 179-195. 
Higgins ET (1997) Beyond pleasure and pain. American Psychologist 52(12): 1280-1300.

Hobfoll SE (1989) Conservation of resources: A new attempt at conceptualizing stress. American Psychologist 44(3): 513-524.

Hoffman BJ, Blair C, Meriac J and Woehr DJ (2007) Expanding the criterion domain? A metaanalysis of the OCB literature. Journal of Applied Psychology 92: 555-566.

$\mathrm{Hu} \mathrm{L}$ and Bentler PM (1999) Cutoff criteria for fit indexes in covariance structure analysis: Conventional criteria versus new alternatives. Structural Equation Modeling 6(1): 1-55.

Jex SM, Wang M and Zarubin A (2007) Aging and occupational health. In: Shultz KS and Adams GA (eds) Aging and Work in the 21st Century. Mahwah, NJ: Lawrence Erlbaum, pp. 199-223.

Kooij TAM, de Lange AH, Jansen PGW and Dikkers JSE (2008) Older workers' motivation to continue to work: Five meanings of age A conceptual review. Journal of Managerial Psychology 23(4): 364-394.

Kooij TAM, de Lange AH, Jansen PGW et al. (2011) Age and work-related motives: Results of a meta-analysis. Journal of Organizational Behaviour 32(2): 197-225.

Laine M, Van der Heijden BIJM, Wickström G et al. (2009) Job insecurity and intent to leave the nursing profession in Europe. The International Journal of Human Resource Management 20(2): 420-438.

Lazarus RS and Folkman S (1984) Stress, Appraisal, and Coping. New York: Springer Publishing Company.

Leary MR and Kowlaski RM (1990) Impression management: A literature review and two component model. Psychological Bulletin 107: 34-47.

Lewchuk W, Clarke M and de Wolff A (2008) Working without commitments: Precarious employment and health. Work, Employment and Society 22(3): 387-406.

Lim VKG (1997) Moderating effects of work-based support on the relationship between job insecurity and its consequences. Work and Stress 11(3): 251-266.

McDonald RP (2010) Structural models and the art of approximation. Perspectives on Psychological Science 5(6): 675-686.

McDonald RP and Ho MHR (2002) Principles and practice in reporting structural equation analyses. Psychological Methods 7(1): 64-82.

MacKinnon DP, Krull JL and Lockwood CM (2000) Equivalence of the mediation, confounding and suppression effect. Prevention Science 1(4): 173-181.

Marescaux E, De Winne S and Sels L (2013) HR practices and HRM outcomes: The role of basic need satisfaction. Personnel Review 42(1): 4-27.

Markland D and Tobin VJ (2010) Need support and behavioural regulations for exercise among exercise referral scheme clients: The mediating role of psychological need satisfaction. Psychology of Sport and Exercise 11(2): 91-99.

Matthews RA, Bulger CA and Barnes-Farrell JL (2010) Work social supports, role stressors, and work-family conflict: The moderating effect of age. Journal of Vocational Behavior 76(1): 78-90.

Molden DC, Lee AY and Higgins ET (2008) Motivations for promotion and prevention. In: Shah $\mathrm{J}$ and Gardner W (eds) Handbook of Motivation Science. New York: Guilford Press, pp. $169-187$.

Moorman RH and Blakely GL (1995) Individualism collectivism as an individual difference predictor of organizational citizenship behavior. Journal of Organizational Behavior 16(2): $127-142$.

Muthén LK and Muthén BO (1998-2012) Mplus User's Guide, 6th edn. Los Angeles: Muthén \& Muthén.

Ng TW and Feldman DC (2010) Organizational tenure and job performance. Journal of Management 36: 1220-1250. 
Organ DW (1988) Organizational Citizenship Behavior: The Good Soldier Syndrome. Lexington, MA: Lexington Books.

Otto K, Hoffmann-Biencourt A and Mohr G (2011) Is there a buffering effect of flexibility for job attitudes and work-related strain under conditions of high job insecurity and regional unemployment rate? Economic and Industrial Democracy 32(4): 609-630.

Podsakoff PM, MacKenzie SB, Paine JB and Bachrach DG (2000) Organizational citizenship behaviors: A critical review of the theoretical and empirical literature and suggestions for future research. Journal of Management 26(3): 513-563.

Podsakoff PM, MacKenzie SB, Lee J-Y and Podsakoff NP (2003) Common method biases in behavioral research: A critical review of the literature and recommended remedies. Journal of Applied Psychology 88(5): 879-903.

Porcellato L, Carmichael F, Hume C et al. (2010) Giving older workers a voice: Constraints on the employment of older people in the North West of England. Work, Employment and Society 24(1): 85-103.

Posthuma RA and Campion MA (2009) Age stereotypes in the workplace: Common stereotypes, moderators, and future research directions. Journal of Management 35(1): 158-188.

Probst T, Stewart S, Gruys M and Tierney B (2007) Productivity, counterproductivity and creativity: The ups and downs of job insecurity. Journal of Occupational and Organizational Psychology 80(3): 479-497.

Reisel WD and Banai M (2002) Comparison of a multidimensional and a global measure of job insecurity: Predicting job attitudes and work behaviors. Psychological Reports 90(3): 913-922.

Roskies E and Louis-Guerin C (1990) Job insecurity in managers: Antecedents and consequences. Journal of Organizational Behavior 11(5): 345-359.

Rothwell A and Arnold J (2007) Self-perceived employability: Development and validation of a scale. Personnel Review 36(1): 23-41.

Ryan RM and Deci EL (2000a) The darker and brighter sides of human existence: Basic psychological needs as a unifying concept. Psychological Inquiry 11: 319-338.

Ryan RM and Deci EL (2000b) Self-determination theory and the facilitation of intrinsic motivation, social development, and well-being. American Psychologist 55(1): 68-78.

Schnake ME (1991) Organizational citizenship: A review, proposed model, and research agenda. Human Relations 44(7): 735-759.

Shimazu A and Schaufeli WB (2007) Does distraction facilitate problem-focused coping with job stress? A 1 year longitudinal study. Journal of Behavioral Medicine 30(5): 423-434.

Shirom A, Gilboa S, Fried Y and Cooper CL (2008) Gender, age and tenure as moderators of workrelated stressors' relationships with job performance: A meta-analysis. Human Relations 61(10): 1371-1398.

Staudinger UM, Marsiske M and Baltes PB (1995) Resilience and reserve capacity in later adulthood: Potentials and limits of development across the life span. In: Cicchetti D and Cohen D (eds) Developmental Psychopathology Vol 2: Risk, Disorder, and Adaptation. New York: Wiley, pp. 801-847.

Staufenbiel T and König CJ (2010) A model for the effects of job insecurity on performance, turnover intention, and absenteeism. Journal of Occupational and Organizational Psychology 83(1): 101-117.

Sverke M and Hellgren J (2002) The nature of job insecurity: Understanding employment uncertainty on the brink of a new millennium. Applied Psychology: An International Review 51(1): 23-42.

Sverke M, Hellgren J and Näswall K (2006) Job Insecurity: A Literature Review. Report No. 1. Stockholm: National Institute for Working Life and the Joint Programme for Working Life Research in Europe (SALTSA). 
Truxillo DM, Cadiz DA and Rineer JR (2012) Designing jobs for an aging workforce. In: Houdmount J, Stavroula L and Sinclair RR (eds) Contemporary Occupational Health Psychology: Global Perspectives on Research and Practice, Vol. 2. Chichester: WileyBlackwell, pp. 109-125.

Van Dalen HP, Henkens CJIM and Schippers JJ (2009) Dealing with older workers in Europe: A comparative survey of employers' attitudes and actions. Journal of European Social Policy 19(1): 47-60.

Van den Broeck A, Vansteenkiste M, De Witte H and Lens W (2008) Explaining the relationships between job characteristics, burnout, and engagement: The role of basic psychological need satisfaction. Work and Stress 22(3): 277-294.

Van den Broeck A, De Cuyper N, De Witte H and Vansteenkiste M (2010a) Not all job demands are equal: Differentiating job hindrances and job challenges in the Job Demands-Resources model. European Journal of Work and Organizational Psychology 19(6): 735-759.

Van den Broeck A, Vansteenkiste M, De Witte H et al. (2010b) Capturing autonomy, competence, and relatedness at work: Construction and initial validation of the Work-related Basic Need Satisfaction scale. Journal of Occupational and Organizational Psychology 83(4): 981-1002.

Van den Broeck A, Sulea C, Vander Elst T et al. (2013) The mediating role of psychological needs in the relation between qualitative job insecurity and counterproductive work behaviour. Manuscript submitted for publication.

Vander Elst T, Baillien E, De Cuyper N and De Witte H (2010) The role of organizational communication and participation in reducing job insecurity and its negative association with workrelated well-being. Economic and Industrial Democracy 32(2): 249-264.

Vander Elst T, Van den Broeck A, De Witte H and De Cuyper N (2012) The mediating role of frustration of psychological needs in the relationship between job insecurity and work-related well-being. Work and Stress 26(3): 252-271.

Van Vuuren T, Klandermans B, Jacobson D and Hartley J (1991) Predicting employees' perceptions of job insecurity. In: Hartley J, Jacobson D, Klandermans B and Van Vuuren T (eds) Job Insecurity: Coping with Jobs at Risk. London: Sage, pp. 65-78.

Vives A, Amable M, Montserrat F et al. (2013) Employment precariousness and poor mental health: Evidence from Spain on a new social determinant of health. Journal of Environmental and Public Health. Available at: http://dx.doi.org/10.1155/2013/978656.

Wallace JC, Edwards BD, Arnold T et al. (2009) Work stressors, role-based performance, and the moderating influence of organizational support. Journal of Applied Psychology 94(1): 254-262.

Webster J, Beehr TA and Christiansen N (2010) Toward a better understanding of the effects of hindrance and challenge stressors on work behavior. Journal of Vocational Behavior 56(1): 68-77.

Webster JR, Beehr TA and Love K (2011) Extending the challenge-hindrance model of occupational stress: The role of appraisal. Journal of Vocational Behavior 79: 505-516.

Wei M, Shaffer PA, Young SK and Zakalik RA (2005) Adult attachment, shame, depression, and loneliness: The mediation role of basic psychological needs satisfaction. Journal of Counseling Psychology 52(4): 591-601.

Widmer PS, Semmer NK, Kälin W et al. (2012) The ambivalence of challenge stressors: Time pressure is associated with both negative and positive well-being. Journal of Vocational Behavior 80(2): 422-433.

\section{Author biographies}

Dave Stynen is postdoctoral researcher at the Department of Epidemiology of Maastricht University, the Netherlands and research fellow at the Faculty of Economics and Business, KU Leuven, Belgium. His main research interests include active ageing and the relationships between 
job characteristics and well-being. Recent work has appeared in Journal of Applied Social Psychology.

Anneleen Forrier is Associate Professor at the Faculty of Economics and Business, KU Leuven, Belgium. Her main research interests include employability, ageing and careers. Her recent publications have appeared in Ageing and Society, Journal of Applied Gerontology, Journal of Managerial Psychology and Gender, Work and Organization.

Luc Sels is Dean of the Faculty of Economics and Business of KU Leuven. He participates in the Research Centre of Organization Studies. His primary substantive research interests centre on labour market projections, active ageing and (corporate) demography, talent management and the features of strong HRM systems. His research has been published in leading scholarly journals such as Journal of Management, Journal of Management Studies, Journal of Applied Psychology, Journal of Organizational Behavior and Human Resource Management Journal.

Hans De Witte is Full Professor in Work Psychology at the Faculty of Psychology and Educational Sciences of the KU Leuven, Belgium, where he is member of the Research Group Work, Organizational and Personnel Psychology (WOPP). He is also appointed as Extraordinary Professor at the North-West University of South Africa (Vanderbijlpark Campus). His research includes the study of the psychological consequences of job insecurity, unemployment, temporary employment and downsizing, as well as mobbing and job stress (e.g. burnout) versus well-being at work (e.g. work engagement). He is member of the European Network of Work and Organizational Psychologists (ENOP). 